Ensino, Saúde e Ambiente - v. 14 n. esp. (2021): Dossiê Paulo Freire para além dos 100 anos: construir utopias, transformar a realidade, p. 01-21.

\title{
Paulo Freire e a Revolução Política do Pensamento Decolonial
}

\section{Paulo Freire and the Political Revolution of the Decolonial Thinking}

\author{
Henry Armand Giroux ${ }^{1}$; Gustavo de Oliveira Figueiredo ${ }^{2}$ \\ ${ }^{1}$ Doutor em Ciências Sociais, McMaster University, Hamilton, Ontário, Canadá - girouxh@mcmaster.ca / \\ https://orcid.org/0000-0003-1637-9142 \\ 2 Doutor em Ciências Humanas, Universidade Federal do Rio de Janeiro, Rio de Janeiro, Brasil - E-mail: \\ gfigueiredo.ufrj@gmail.com / ORCID https://orcid.org/0000-0003-2724-8826
}

\section{Palavras-chave: contexto decolonial; liberdade; educação; cultura; esperança}

\section{Keywords:} decolonial context; freedom; education; culture; hope
RESUMO: Argumentamos nesse ensaio que a obra de Paulo Freire pode ser lida como um texto decolonial e que os educadores progressistas devem se engajar de forma radical na transgressão de fronteiras para reconstruir a obra de Freire na especificidade de seu contexto histórico e político. Isso significa destacar a problemática de uma política de colonização situada no privilégio e poder do Ocidente com o objetivo de discutir como a questão ideológica de tal posição pode propor uma leitura distorcida da obra de Freire. Ao mesmo tempo, destacamos que Freire torna-se um cruzador de fronteiras revolucionário engajado no diálogo produtivo com os autores de seu tempo, produzindo uma obra crítica em que as relações sociais dominantes, ideologias e as práticas que apagam a especificidade da voz dos povos colonizados possam ser desafiadas e superadas. Em sua luta em favor da liberdade, o autor torna a educação e a cultura elementos centrais para a política e propõe ideias capazes de romper com a tradição conservadora e de restaurar a esperança na capacidade dos seres humanos em transformar a realidade e reescrever a história.

ABSTRACT: We argue in this essay that Paulo Freire's work can be read as a decolonial text and that progressive educators must radically engage in transgressing boundaries to reconstruct Freire's work in the specificity of its historical and political context. This means highlighting the problematic of a colonization policy situated in the privilege and power of the West to discuss how the ideological issue of such a position can propose a distorted reading of Freire's work. At the same time, we emphasize that Freire becomes a revolutionary frontier-crosser engaged in productive dialogue with the authors of his time, producing a critical work in which dominant social relations, ideologies, and practices that erase the specificity of colonized peoples' voices can be challenged and overcome. In his fight for freedom, the author makes education and culture central elements for politics and proposes utopian ideas capable of breaking with conservative tradition and restoring hope in the ability of human beings to transform reality and rewrite the story. 
Ensino, Saúde e Ambiente - v. 14 n. esp. (2021): Dossiê Paulo Freire para além dos 100 anos:

construir utopias, transformar a realidade, p. 01-21.

As Epistemologias Freireanas

\section{RELEVÂNCIA POLÍTICA DA OBRA DE FREIRE NAS LUTAS POR LIBERDADE E TRANSFORMAÇÃO SOCIAL}

Dia 19 de setembro de 2021 foi o aniversário de Paulo Freire. Houve e haverá muitas comemorações do centenário de seu nascimento. E muitos irão tratá-lo como um ícone ao invés do revolucionário que ele realmente foi. Ao fazê-lo, falarão de Freire com uma espécie de reverência despolitizante que costumamos associar ao louvor vazio reservado às celebridades mortas. As universidades privadas norte americanas publicarão declarações celebrando seu trabalho, oferecendo-se como modelos de mudança radical, o que, obviamente, é o oposto do que elas acreditam (STYGALL, 1989). Esse desvio é compreensível em uma época de ignorância fabricada, com adoração de uma cultura da celebridade em uma época onde a memória histórica se torna perigosa e a dissidência de ideias uma maldição. Freire foi um revolucionário cuja paixão pela justiça social e resistência política foi acompanhada por sua crítica ao capitalismo neoliberal e aversão a autoritários de todos os matizes políticos. Simplificando, ele não era apenas um intelectual público, mas também um lutador pela liberdade. E os atuais ataques neofascistas a ele dirigidos pelo governo Bolsonaro, deixam claro quão relevante, inovador e "perigoso" é o seu trabalho até hoje.

Uma das contribuições mais importantes de Freire foi a politização da cultura. Ele via a cultura como um terreno de luta que refletiria as disputas sociais e que seria capaz de redistribuir poder. Ele rejeitou a noção marxista vulgar de que a cultura seria simplesmente um reflexo das forças econômicas. Ele não apenas conectou a cultura com as relações sociais de produção e legitimação da guerra de classes, da destruição ecológica e de várias formas de privilégio, mas também entendeu que a cultura sempre esteve relacionada ao poder como uma força enormemente influente. Isso é especialmente verdadeiro na era das mídias digitais e redes sociais, com seu poder de definição dos diversos modos de inclusão, criação de consentimento legítimo, produção de formas específicas de agência e reprodução de relações desiguais de poder dentro e fora dos Estados-nação. Ele enfatizou fortemente o papel da linguagem e dos valores nas lutas por identidade e recursos, analisando criticamente o funcionamento dos meios de comunicação de diferentes organizações da esfera pública, como escolas, mídia de massa, aparatos corporativos e outras esferas sociais. 
Ensino, Saúde e Ambiente - v. 14 n. esp. (2021): Dossiê Paulo Freire para além dos 100 anos: construir utopias, transformar a realidade, p. 01-21.

\section{As Epistemologias Freireanas}

Seu trabalho sobre alfabetização se concentrou em como as práticas culturais capitalistas colocaram certas formas de agência comercializada em prática, definindo os contornos do espaço público e despolitizando as pessoas por meio da linguagem de comandos, enquanto mercantilizavam e privatizavam tudo. Cultura e alfabetização, para Freire, oferecem às pessoas um espaço para desenvolver novos modos de agência, resistência coletiva e vínculos emocionais que abraçam formas fortalecedoras de solidariedade. Para Freire, os terrenos da cultura, da alfabetização e da educação eram os terrenos em que os indivíduos adquiriam consciência de sua posição e disposição para lutar por dignidade, igualdade social e liberdade. Para Freire, a cultura era um campo de batalha, um local de luta. E ele reconhecia, à maneira de Gramsci, que toda relação de dominação é "pedagógica e ocorre entre as diferentes forças que a compõem".

Ao tornar a educação central para a política, Freire conectou ideias ao poder e deu consciência crítica à alfabetização para intervir no mundo, na luta por justiça econômica, social, de gênero e racial. Ele nunca separou o sofrimento e os constrangimentos massivos impostos pela desigualdade da esfera política e, ao não fazê-lo, reuniu as condições necessárias, por mais específicas que fossem, para a resistência e o enfrentamento dos constrangimentos que pesavam sobre a vida das pessoas. Freire acreditava que todos os seres humanos poderiam "sermais" e teriam a capacidade de ser intelectuais, de pensar criticamente, de estranhar o familiar e de lutar individual e coletivamente contra as máquinas destruidoras da imaginação nas zonas de abandono ético, político e social em que se transformaram algumas democracias, versões atualizadas do Estado fascista.

Seu trabalho não era simplesmente sobre métodos, mas sobre promover a mudança individual e social de uma forma que desse voz aos que não têm e poder aos que são considerados descartáveis. Freire era um lutador pela liberdade que acreditava profundamente em um futuro em que a democracia radical fosse uma realidade. Ele era um utópico destemido para quem a esperança não era simplesmente uma ideia, mas uma maneira diferente de pensar, a fim de agir de outra forma e transformar a história. O trabalho educativo e político de Freire se assentou num ideal ético e num sentido de responsabilidade que hoje é atacado, o que atesta a sua importância e a necessidade de sua defesa. Há também a necessidade de evitar que seja apropriado pelas elites governantes. É importante estendê-lo a novos círculos econômicos, culturais e sociais para os quais ele é desesperadamente necessário na luta contra 
Ensino, Saúde e Ambiente - v. 14 n. esp. (2021): Dossiê Paulo Freire para além dos 100 anos: construir utopias, transformar a realidade, p. 01-21.

\section{As Epistemologias Freireanas}

a política fascista emergente, especialmente na forma bizarra que tem tomado em diversos países da América Latina e especialmente no Brasil desde o golpe de Estado de 2016.

A obra de Paulo Freire continua a exercer forte influência sobre uma variedade de educadores liberais e radicais. Em alguns setores, seu nome tornou-se sinônimo do próprio conceito e prática da pedagogia crítica. Cada vez mais, o trabalho de Freire se tornou a referência padrão para se engajar no que é muitas vezes referido como ensino para o pensamento crítico, pedagogia dialógica ou alfabetização crítica. Como a obra de Freire permeou desde as origens de sua produção no Brasil, passando pela América Latina e África até as fronteiras híbridas da América do Norte, o autor tem sido frequentemente apropriado por acadêmicos, educadores e outros profissionais que habitam a ideologia do Ocidente e que muitas vezes o reduzem a uma técnica ou método pedagógico. Claro, para justificar essa apropriação indevida, as descrições geralmente invocam termos como "politicamente carregado", "problematizador", ou a obrigatória “educação para consciência crítica" e muitas vezes, inclusive, contradizem a própria obra do autor ao adotar receitas pedagógicas tradicionais e opressoras, vestidas com o jargão de abstratos rótulos progressivos, que apagam sua relevância como um projeto político de luta, resistência e enfrentamento. Um enfrentamento construído em meio a lutas concretas no desenvolvimento de uma prática pedagógica revolucionária. O que tem sido cada vez mais perdido na apropriação ocidental que se faz da obra de Freire é a profunda e radical natureza de sua teoria e prática como discurso decolonial.

Mais especificamente, o trabalho de Freire é frequentemente apropriado e ensinado "sem qualquer consideração sobre o imperialismo e sua representação cultural. Esta lacuna em si sugere a contínua dissimulação ideológica do imperialismo hoje" (YOUNG, 1990). Isso sugere que a obra de Freire foi apropriada de maneiras que o desnudam de alguns de seus mais importantes conhecimentos. Da mesma forma, isso atesta o funcionamento de uma política de globalização a serviço do privilégio e do poder que impede o cruzamento das fronteiras culturais, políticas e textuais de modo a negar a especificidade do outro para reimpor o discurso e prática da hegemonia colonial.

Argumentamos que a obra de Paulo Freire deve ser lida como um texto decolonial e que os educadores progressistas devem se engajar de forma radical na travessia de fronteiras para reconstrução de sua obra, na especificidade da sua construção histórica e política. Especificamente, isso significa destacar a problemática de uma política de colonização situada 
Ensino, Saúde e Ambiente - v. 14 n. esp. (2021): Dossiê Paulo Freire para além dos 100 anos: construir utopias, transformar a realidade, p. 01-21.

\section{As Epistemologias Freireanas}

no privilégio e poder do Ocidente, e como a questão ideológica de tal posição constrói uma leitura distorcida da obra de Freire. Ao mesmo tempo, ao tornar-se um cruzador de fronteiras engajado em um diálogo produtivo com os outros, Freire produz um espaço em que as relações sociais dominantes, com suas ideologias e práticas que apagam a especificidade da voz dos povos colonizados, possam ser desafiadas e superadas.

Freire acreditava, antes de mais nada, que a educação estava ligada à mudança social e que as questões de consciência e identidade eram essenciais e tornavam a pedagogia central para a própria política. Para Freire, educação e escolaridade faziam parte de uma luta mais ampla contra o capitalismo, o neoliberalismo, o autoritarismo, o fascismo e a despolitização e instrumentalização da educação. A ação direta, a educação política e a política cultural definiram para ele novas estratégias de resistência e novos entendimentos da relação entre poder e cultura e como isso moldava questões de identidade, valores e compreensão do futuro. A pedagogia e a alfabetização eram políticas porque estavam conectadas à luta pela agência, às relações contínuas de poder e às pré-condições para conectar o conhecimento e os valores ao desenvolvimento de cidadãos críticos, ativos e engajados.

\section{CRUZANDO AS FRONTEIRAS DA DOMINAÇÃO INTELECTUAL, POLÍTICA E CULTURAL}

A fim de compreender a obra de Freire em termos de sua importância histórica e política, os educadores e trabalhadores culturais têm de se tornar transfronteiriços. Isso significa que professores e outros intelectuais têm que se despedir do naturalismo cultural e cruzar as fronteiras teóricas e ideológicas que os encerram na segurança "daqueles lugares e espaços que herdamos e ocupamos, que enquadram nossas vidas em muitas formas específicas e concretas" (BORSA, 1990). Ser um intelectual cruzador de fronteiras sugere que é preciso reinventar tradições fora do discurso de submissão, reverência e repetição, mas assumir uma posição de transformação e crítica social. Isso é, "Deve-se construir um discurso de diferença em relação a essa tradição colonizadora e isso implica, ao mesmo tempo, continuidades e descontinuidades" (LACLAU, 1988, p.12). Ao mesmo tempo, cruzar a fronteira envolve um trabalho intelectual, não apenas em sua especificidade acadêmica e parcialidade, mas também em termos de funcionar como parte de um discurso de invenção e construção, ao invés de um discurso de reconhecimento cujo fim se reduz a revelar e transmitir verdades universais. Neste caso, é importante destacar o trabalho intelectual como 
Ensino, Saúde e Ambiente - v. 14 n. esp. (2021): Dossiê Paulo Freire para além dos 100 anos: construir utopias, transformar a realidade, p. 01-21.

\section{As Epistemologias Freireanas}

sendo forjado na intersecção da contingência concreta e da história, decorrente não dos "campos de caça exclusivos de uma elite, mas de todos os pontos que conformam o tecido social" (LACLAU, 1988, p. 24).

Essa tarefa se torna ainda mais difícil com Freire porque as fronteiras que definem seu trabalho mudaram ao longo do tempo de maneira paralela ao seu próprio exílio e peregrinação por países como Chile, México, Estados Unidos, Suíça e de volta ao Brasil. A obra de Freire não se baseia apenas em discursos europeus, mas também no pensamento e na linguagem própria dos teóricos da África e América Latina. O projeto político-pedagógico de Freire levanta enormes dificuldades para os educadores que situam a sua obra na linguagem reificada de metodologias vazias que consagram a técnica em detrimento do teórico e político.

Freire foi um exilado para quem estar em casa é muitas vezes equivalente a ser "semteto" e para quem sua própria identidade e a identidade dos outros são vistas como locais de luta pela política de representação, exercício de poder, e reinvenção da memória social. É importante notar que o conceito de "casa" usado aqui não se refere exclusivamente a esses lugares em que se dorme, come, cria filhos e sustenta um certo nível de conforto. Para alguns, esta noção particular de "casa" é muito mítica, especialmente para aqueles que literalmente não têm casa neste sentido; também se torna uma reificação quando significa um lugar de segurança que exclui as vidas, identidades e experiências do outro, ou seja, quando se torna sinônimo de capital cultural dos sujeitos brancos de classe média. "Casa", no sentido que estamos usando, refere-se a aspectos culturais e sociais que demarcam as fronteiras políticas entre os diversos espaços de conforto, sofrimento, abuso e segurança definindo a localização de um indivíduo ou grupo. Afastar-se de "casa" é questionar, na história, em termos semióticos e estruturais, como os limites e significados de "casa" são construídos de maneira evidente, muitas vezes fora da crítica. "Casa é sobre aqueles espaços culturais e formações sociais que funcionam hegemonicamente ou como locais de resistência. No primeiro caso, a "casa" é segura em virtude de suas exclusões repressivas e localização hegemônica fora da história. No segundo caso, o lar torna-se uma forma de "desabrigo", um local de mudança de identidade, resistência e oposição que reúne condições para uma outra formação social e cultural.

Mas a cultura também produz limites que distinguem a coletividade do que está fora dela e que definem as organizações dentro dessa coletividade. "Sem-teto", por exemplo, é um conceito facilitador associado ao espaço civil e político que a hegemonia não pode suturar, um espaço em que atos alternativos e intenções alternativas que ainda não são articulados 
Ensino, Saúde e Ambiente - v. 14 n. esp. (2021): Dossiê Paulo Freire para além dos 100 anos: construir utopias, transformar a realidade, p. 01-21.

\section{As Epistemologias Freireanas}

como instituições sociais, ou mesmo projetos sociais, podem sobreviver. "Sem-teto", então, é uma situação em que a potencialidade utópica pode perdurar. Para Freire, a tarefa de ser intelectual sempre foi forjada no âmbito de sem-teto: entre as diferentes zonas do teórico e do cultural; entre as fronteiras de culturas não europeias e europeias. Com efeito, Freire é um intelectual fronteiriço, cuja lealdade não foi a uma classe e cultura específicas, como na noção de Gramsci do intelectual orgânico; em vez disso, os escritos de Freire incorporam um modo de luta discursiva e oposição que não só desafia a máquina opressora do Estado, mas também simpatiza com a formação de novos sujeitos e movimentos culturais engajados na luta pelos valores modernistas de liberdade, igualdade e justiça. Em parte, isso explica o interesse de Freire por educadores, feministas e revolucionários na África e América Latina.

É esse sentido de "sem-teto", essa constante passagem para terrenos de alteridade, que caracteriza a vida e a obra de Freire. É como um exilado, um intelectual que se coloca entre as diferentes culturas, epistemologias e limites espaciais. Foi nesses espaços entre mundos que Freire situou sua própria política de localização, tornando-se um cruzador de fronteiras. Como intelectual fronteiriço, ele rompe a relação entre a identidade do indivíduo e a subjetividade coletiva. Ele torna visível uma política que liga o sofrimento humano a um projeto de futuro, ao "Inédito-viável", não como um mergulho estático em uma textualidade desencarnada das lutas humanas, mas como uma política de educação forjada nos deslocamentos políticos e materiais dos regimes dominadores que exploram, oprimem, expulsam, mutilam e arruínam a vida humana. Como intelectual da fronteira, Freire ocupa um terreno de "falta de moradia" no sentido pós-moderno, que sugere a impossibilidade de um fechamento ideológico e hegemônico que não promova o alívio das tensões e contradições incessantes que informam tais identidades, lutas e projetos. Lembremos que, para Freire, o ser humano sempre pode "ser-mais".

\section{A INVESTIGAÇÃO-AÇÃO-PARTICIPATIVA COMO FUNDAMENTO POLÍTICO E EPISTEMOLÓGICO PARA ORIGEM E DESENVOLVIMENTO DO PENSAMENTO DECOLONIAL NA AMÉRICA LATINA}

Ao fazer uma análise da virada decolonial na América Latina, Restrepo e Rojas (2010) afirmam que a colonialidade é um padrão ou uma matriz de poder que estrutura o sistema mundial moderno no qual trabalham, subjetividades, saberes, lugares e seres humanos e que opera um projeto de desenvolvimento baseado na ciência positivista moderna, em nome da qual se intervém nos territórios, grupos, conhecimentos, corpos, subjetividades e práticas. 
Ensino, Saúde e Ambiente - v. 14 n. esp. (2021): Dossiê Paulo Freire para além dos 100 anos: construir utopias, transformar a realidade, p. 01-21.

\section{As Epistemologias Freireanas}

Dessa forma, a luta decolonial está radicalmente comprometida em cruzar fronteiras para recuperar a especificidade de sua construção histórica e política. Segundo Giroux (1992a), descolonizar significa problematizar uma política de localização referenciada no privilégio, poder e peso ideológico da Europa ocidental. Ao mesmo tempo, tornar-se um cruzador de fronteiras engajado em um diálogo produtivo com os outros significa produzir um espaço no qual as relações sociais, ideologias e práticas dominantes apagam a especificidade da voz do outro, devendo ser desafiadas e superadas. Por ser uma passagem de fronteira, sugere que é necessário reinventar tradições fora do discurso de submissão, reverência e repetição com luta, criatividade, transformação e crítica.

O fundamento epistemológico que sustenta o pensamento decolonial na América Latina foi um processo coletivo que se beneficiou do trabalho criativo e do debate entre pessoas do continente interessadas em investigar temas característicos de suas próprias realidades sociais, principalmente problemas relacionados à educação, cultura e produção de conhecimento popular, transgredindo as fronteiras impostas pelos colonizadores e desafiando as relações de poder. Ortiz \& Borjas (2008) confirmam que, durante a luta contra as ditaduras militares em vários países da América Latina entre 1960 e 1980, se fermentava uma ampla corrente de pensamento em que convergiam diversos atores sociais como professores, escritores, poetas, sociólogos, líderes comunitários, artistas, trabalhadores industriais, ativistas urbanos, analistas organizacionais, políticos, cientistas e educadores sociais. De todos esses campos - fermentados pelos movimentos sociais, pela educação popular, pela teologia da libertação, pelos meios de comunicação alternativos e pelos teóricos da Investigação-AçãoParticipativa - surge uma convergência interdisciplinar que foi capaz de produzir e legitimar conhecimentos próprios dos povos que lutam contra a hegemonia colonial, permitindo que setores considerados subalternos pela sociedade pudessem compreender a complexidade da realidade e lutar para transformá-la.

Desde o início dos anos 1970, o sociólogo colombiano Orlando Fals Borda e o educador brasileiro Paulo Freire já haviam proposto o uso do termo Investigação-AçãoParticipativa para descrever uma abordagem epistemológica alternativa ao modelo sociológico universalista de origem europeia. Ambos os pensadores, de certa forma, orientaram esse delicado percurso de construção de sólido referencial epistemológico decolonial. Por um lado, as contribuições de Fals Borda (1968; 1987; 1999; 2000; 2008; 2015) revelam que o peso da tradição, a natureza da estrutura de classes na América Latina e 
Ensino, Saúde e Ambiente - v. 14 n. esp. (2021): Dossiê Paulo Freire para além dos 100 anos: construir utopias, transformar a realidade, p. 01-21.

\section{As Epistemologias Freireanas}

a interferência de interesses externos, atrasaram a ação necessária para a emancipação do continente. Por outro lado, Freire $(1979 ; 1980 ; 1987$; 1997) criticava a suposta neutralidade da ciência, afirmando que quando o sujeito não se posiciona diante da perpetuação do modus operandi que sustenta a dominação e a opressão, ele autoriza que essa suposta neutralidade contribua para a perpetuação da situação de desigualdade social e expropriação colonial. Fals Borda (1999) lembra como nos países em desenvolvimento o pensamento e a ação se articulavam, "combinando coração e cabeça" para propor técnicas e procedimentos que pudessem satisfazer a angústia dos pesquisadores sociais na qualidade de tanto de cidadãos quanto de cientistas. A metodologia da pesquisa-ação participativa centra-se no que se denomina " tensões estratégicas " - um conjunto de esquemas derivados do conceito clássico de "práxis" (ação-reflexão-ação), aos quais foram agregados elementos, culturalmente éticos e étnicos. Para Freire (1993) a ideia de práxis é caracterizada por um complexo de ideias, conceitos, esperanças, dúvidas, valores e desafios na interação dialética com suas oposições que buscam sua realização.

O primeiro simpósio Mundial da Investigação-Ação-Participação, realizado em Cartagena, Colômbia, no ano de 1977, caracteriza-se como um evento decisivo ao promover o encontro das vocações teórico-epistemológicas e das experiências práticas de resistência e luta na América Latina. Nele, sustentou-se a tese sociológica da possibilidade de resgate histórico local e de construção do conhecimento regional a partir das práxis de intervenção e participação social, que antecipou a reorientação das ciências sociais e humanas, inclusive nos Estados Unidos e na Europa. Esse evento revelou como o fluxo de pensamento do centro para a periferia pode organizar uma resistência à colonialidade, favorecendo e ampliando uma cooperação sul-sul. A Federação Colombiana de Educadores (FECODE, 2006) caracteriza a investigação-ação-participativa como um dispositivo de resistência ao processo de produção de conhecimento a partir do modelo colonial, constituindo-se como alternativa epistemológica latino-americana própria e configurando-se como método de aprendizagem mútua entre intelectuais e pequenos grupos comunitários na busca de possíveis soluções para os conflitos políticos locais com participação social. Essa perspectiva de movimento revolucionário e de crítica à dominação colonial pode ser ilustrada por um depoimento sobre essa práxis coletiva:

Éramos sociólogos, antropólogos, economistas, teólogos, artistas, fazendeiros, educadores e assistentes sociais. Tratava-se, portanto, de um grupo diverso e complexo, alguns dos quais teriam decidido abandonar as rotinas universitárias e se dedicar a buscas alternativas. Na Índia, o grupo camponês de Bhoomi-Sena 
Ensino, Saúde e Ambiente - v. 14 n. esp. (2021): Dossiê Paulo Freire para além dos 100 anos: construir utopias, transformar a realidade, p. 01-21.

\section{As Epistemologias Freireanas}

(Exército da Terra, com seus intelectuais orgânicos Da Silva, Wignaraja, Rahman e outros) estava florescendo ; no Brasil, Paulo Freire e Darcy Ribeiro enfrentaram a ditadura militar e alimentaram a "consciência"; no México, Rodolfo Stavenhagen pôs em prática seu célebre artigo sobre "descolonizar as ciências sociais"; y en Colombia, el padre Camilo Torres, María Cristina Salazar y otros colegas ponían las bases de la "acción comunal" y predicaban la línea nacionalista con temas de lucha contra el latifundio y por los derechos humanos, así como la búsqueda de raíces históricas de os povos. (FALS- BORDA, 2008, p.7)

Por outo lado, Quijano (2014) também teve uma contribuição muito relevante ao desenvolver uma crítica do eurocentrismo e do colonialismo científico na América Latina, declarando a necessidade de uma independência intelectual das metrópoles colonizadoras, estimulando nossos talentos regionais, respeitando nossa dignidade histórica e combatendo o modelo patriarcal colonial. Isso não significa que as contribuições culturais e científicas do restante do mundo sejam rejeitadas. A independência intelectual anunciada por Quijano significa que a reprodução dos mesmos pressupostos dos colonizadores à nossa realidade social deve ser criticada e ultrapassada.

Pestaña \& Alcázar (2009) destacam que os aspectos metodológicos da investigaçãoação-participação se articulam de forma diferente do método científico convencional, uma vez que a forma de organização da pesquisa é menos autoritária e mais compartilhada. No mesmo sentido, Figueiredo (2015) afirma que um uma das características mais salientes do surgimento de uma epistemologia das ciências sociais é sua relação com o desenvolvimento do pensamento crítico na América Latina, demonstrando a preocupação com os limites da sociedade atual e com as possibilidades de configuração de uma ordem humana e justa.

É provável que uma das contribuições mais importantes para as ciências sociais e humanas no contexto contemporâneo seja a teoria decolonial desenvolvida na América Latina. Em um dos textos mais relevantes sobre essa teoria decolonial, Mignolo (2008) revela a importância da desobediência epistêmica como uma opção decolonial que produz o sentido da identidade na política. A desobediência epistêmica é uma crítica ao paradigma da racionalidade e colonialidade modernas. Ele ainda argumenta que isso é necessário para desencadear um pensamento epistêmico próprio, a partir de nossas latitudes, destacando a importância de construir teorias sociais e organizar ações políticas com base na contestação de identidades que foram atribuídas por discursos imperiais, sendo, portanto, necessário desnaturalizar o racismo, a dominação imperial e o patriarcalismo que fundam a ciência 
Ensino, Saúde e Ambiente - v. 14 n. esp. (2021): Dossiê Paulo Freire para além dos 100 anos: construir utopias, transformar a realidade, p. 01-21.

\section{As Epistemologias Freireanas}

moderna. Se essas identidades eram dominantes, patriarcais, raciais, opressoras, genocidas e misóginas, a construção de uma nova identidade política para a sociedade latina é, portanto, uma forma decolonial de pensar e agir, um ato de criação científica que satisfaz tanto as exigências do método, quanto da epistemologia do conhecimento científico, fundamentando ações concretas e práticas na luta e resistência por uma práxis decolonial para a sociedade latino-americana.

\section{PAULO FREIRE COMO UM REVOLUCIONÁRIO TRANSGRESSOR DE FRONTEIRAS}

Paulo Freire, como um educador crítico e trabalhador cultural, sempre foi extremamente consciente das intenções, objetivos e efeitos do cruzamento das fronteiras impostas pela dominação colonial. Com sua própria práxis, ele pôde analisar como tais movimentos de transgressão de limites impostos oferecem uma oportunidade para novos sujeitos, identidades e relações sociais que podem organizar a resistência para lutar contra dispositivos de dominação e opressão.

Entretanto, isso não significa que a obra de Freire se desenvolveu sem contradições. Para exemplo, Freire tentou reconciliar uma política emancipatória de alfabetização e uma luta pela identidade e diferença com certos elementos problemáticos do modernismo. As tentativas incessantes de Freire em construir uma nova linguagem, produzir novos espaços de resistência, imaginar novos fins e criar as oportunidades de alcançá-los, às vezes, ficavam limitadas, ao totalizar narrativas e articular binarismos que menosprezam o que é mutuamente contraditório e poderiam reduzir o caráter múltiplo da dominação e também das lutas. Nesse sentido, a confiança na emancipação como um elemento da luta de classes, às vezes torna invisível o modo como as mulheres são submetidas de forma diferente às estruturas patriarcais. Da mesma forma, seu apelo aos sujeitos dominantes para se comprometer com as lutas contra a opressão, minimizou a natureza complexa, múltipla e contraditória de subjetividade humana.

Também, a referência de Freire às "massas", ou oprimidos, como estando inscritos em uma cultura de silêncios parecia estar em desacordo com as formas variadas de dominação sob as quais esses grupos estão submetidos e em alguns aspectos era contraditória à própria perspectiva de Freire sobre as diversas formas pelas quais os oprimidos lutam e se manifestam 
Ensino, Saúde e Ambiente - v. 14 n. esp. (2021): Dossiê Paulo Freire para além dos 100 anos: construir utopias, transformar a realidade, p. 01-21.

\section{As Epistemologias Freireanas}

na prática política. Embora seja crucial reconhecer o brilho teórico e político que informou grande parte de sua obra, e todo seu vanguardismo, isso não nos impede de revelar alguns binarismos que informam a Pedagogia do Oprimido (FREIRE, 1987), mas também nos limites de suas Cartas à Guiné-Bissau (FREIRE, 2014), particularmente nas seções em que Freire argumenta que a cultura das massas deve desenvolver-se com base na ciência e que a pedagogia emancipatória deve ser alinhada com a luta pela reconstrução nacional. Sem abordar adequadamente as contradições que essas questões levantam entre os objetivos de Estado, o discurso da vida cotidiana, e o potencial para a violência pedagógica sendo feita em nome da política, o trabalho de Freire está exposto à acusação feita por alguns teóricos de ser uma obra excessivamente totalizante. Mas isso pode ser lido menos como uma crítica redutora de Obra de Freire do que como uma indicação da necessidade de sujeitá-la a todas as formas de crítica social, para análises que envolvem seus pontos fortes e limitações como parte de um diálogo mais amplo a serviço de uma política emancipatória.

Algumas contradições na obra de Freire nos oferecem uma série de questões que precisam ser abordadas por educadores críticos, não apenas sobre o trabalho de Freire, mas também os sobre seus próprios trabalhos. Por exemplo: o que acontece quando a linguagem do educador não é igual à do oprimido? Como é possível ser vigilante para não assumir noções de linguagem, política e racionalidade que minam o reconhecimento da própria parcialidade e das vozes e experiências de outros? Como explorar a contradição entre validar certas formas de pensamento e a tarefa pedagógica de ajudar os estudantes a assumir seu protagonismo ao invés de simplesmente seguir os ditames da autoridade, independentemente de quão radical é o projeto informado por tal autoridade?

O recurso de Freire a binarismos como oprimido vs. opressor, resolução de problemas vs. problematização, ciência vs. magia, enfureceu-se bravamente contra línguas dominantes e configurações de poder que se recusaram a abordar suas próprias políticas, apelando para os imperativos de polidez, objetividade, e neutralidade. Aqui Freire avança na fronteira entre o discurso modernista e o discurso anticolonialista. Ele luta contra o colonialismo, mas ao fazê-lo frequentemente reverte, em vez de romper, sua problemática básica. Benita Parry (1987) localiza um problema semelhante na obra de Frantz Fanon: "O que acontece é que a heterogeneidade é reprimida nas figuras monolíticas e estereótipos de representações colonialistas.

Entretanto, claro que não pode ser esquecido que a força do discurso inicial de Freire repousa, em parte, com o fato de tornar visível não apenas a luta ideológica contra a 
Ensino, Saúde e Ambiente - v. 14 n. esp. (2021): Dossiê Paulo Freire para além dos 100 anos: construir utopias, transformar a realidade, p. 01-21.

\section{As Epistemologias Freireanas}

dominação e o colonialismo, mas também a substância material da dor e sofrimento humano, forjada no calor de lutas de vida ou morte. Porém, em seus trabalhos posteriores, principalmente na parceria com Donaldo Macedo (FREIRE e MACEDO, 1987), em suas numerosas entrevistas e em seus livros dialogando com autores como Ira Shor, Antonio Faundez (FREIRE e FAUNDEZ, 1989); Ira Shor (FREIRE e SHOR, 1987); Peter Leonard (LEONARD e McLAREN, 2002), e Myles Horton (HORTON e FREIRE, 1990) Paulo Freire empreende uma forma de crítica e política cultural que empurra os limites que invocam o discurso do sujeito unificado, humanista, histórico, universal, como agentes da racionalidade iluminista. Recusando o privilégio de sentar-se sobre seu reconhecimento internacional, Freire avançou sempre na direção de constituir-se como um intelectual fronteiriço, situado no universo mutante e adotou para si mesmo uma postura de constante mudança. São nesses diálogos que obtemos mais indicações de alguns dos princípios que podem definir Freire como um revolucionário. São nesses trabalhos que vemos vestígios, imagens e representações de um projeto político inextricavelmente ligado à autoformarão. Ou seja, é aqui onde Freire é mais preciso em desvendar e desmontar ideologias e estruturas de dominação, à medida que elas surgem em seu confronto com as exigências contínuas da vida diária, manifestando-se de forma diferente nas tensões entre as periferias e os centros de poder que passaram a caracterizar um pensamento pós-colonial.

Em seu último livro, Pedagogia da Esperança, Freire (2021) invoca e constrói elementos de uma crítica social que compartilha uma afinidade com vertentes emancipatórias do discurso pós-moderno e pós-estruturalista. Nessa obra ele relativiza uma ética transcendente, o funcionalismo epistemológico e a teleologia política, desenvolvendo um discurso mais provisório, embora sempre ético e político, mas agora um discurso sujeito ao tempo, ao jogo da história, das culturas e do poder. Como um transgressor de fronteiras, ele constantemente reexamina sua obra e levanta questões sobre que tipo de fronteiras precisam ainda ser cruzadas e revisitadas, que tipo de identidades estão sendo refeitas e reconfiguradas, dentro de novas fronteiras históricas, sociais e políticas, e quais os efeitos de tais cruzamentos para a redefinição de uma prática política e pedagógica crítica e comprometida com a transformação social. Para Freire, a pedagogia é vista como uma prática cultural e política que não ocorre apenas nas escolas, mas em todas as esferas culturais. Neste caso, todo trabalho cultural é pedagógico e os trabalhadores culturais habitam uma série de locais que incluem, mas não se limitam às escolas. 
Ensino, Saúde e Ambiente - v. 14 n. esp. (2021): Dossiê Paulo Freire para além dos 100 anos: construir utopias, transformar a realidade, p. 01-21.

\section{As Epistemologias Freireanas}

Em um diálogo fértil com Antonio Faundez (FREIRE e FAUDEZ, 1989), Freire fala sobre sua formação no exílio como um rico processo de cruzar fronteiras. Utilizando a metáfora do andarilho, ele escreve que foi viajando por todo o mundo, pela África, pela Ásia, pela Austrália e Nova Zelândia, pelas ilhas do Pacífico Sul e através de toda América Latina, Caribe, América do Norte e Europa, passando, em resumo, por diferentes partes do mundo, como um exilado, que ele teria compreendido melhor o seu próprio país. Foi por vê-lo a partir de uma certa distância, que ele o pôde entender melhor. Era ao ser confrontado com um outro eu, que ele descobria mais facilmente sua própria identidade. E assim, superou o risco que os exilados às vezes correm de serem muito remotos em seus trabalhos como intelectuais, distantes das experiências reais, mais concretas, e de ser um tanto ingênuos, e até um tanto contentes, porque estão perdidos em um jogo de palavras, o que Freire chamava de maneira bem-humorada de "especializar-se no balé de conceitos".

Ler a obra de Freire nos últimos quinze anos nos aproxima do insight de Adorno (apud GIROUX, 1992b) quando o autor afirma que, "faz parte da moralidade não estar em casa" Adorno também era um exilado, furioso contra o horror e mal de outra era, mas ele também insistia que era o papel de intelectuais, desafiar aqueles lugares limitados pelo terror, exploração, e sofrimento humano. Ele também pediu que os intelectuais se recusassem a obedecer e os conclamava para que transgredissem esses sistemas de padronização, mercantilização e administração, pressionando a serviço de uma ideologia e linguagem ocupadas, ou cúmplices, dos centros de poder. Cabe ressaltar, entretanto, que Freire difere intelectual e politicamente de Adorno por haver em seu trabalho um senso mais profundo de ruptura, transgressão e esperança. Isso é evidente em seu apelo para que educadores, críticos sociais e trabalhadores culturais moldem uma noção de política e pedagogia fora das fronteiras disciplinares estabelecidas pelos colonizadores; fora da divisão entre alta cultura e cultura popular; fora de estáveis noções de identidade; fora de esferas públicas homogêneas; e fora dos limites que separam o desejo humano e suas emoções da racionalidade, que separam o corpo da mente. $\mathrm{O}$ exilado sabe que em um mundo secular e contingente, as casas são sempre provisórias. Fronteiras e barreiras que nos encerram na segurança de familiares territórios também podem se tornar prisões e muitas vezes são defendidas além da razão ou da necessidade. Exilados cruzam fronteiras, quebram barreiras de pensamento e experiência. (GIROUX, 1992b) 
Ensino, Saúde e Ambiente - v. 14 n. esp. (2021): Dossiê Paulo Freire para além dos 100 anos: construir utopias, transformar a realidade, p. 01-21.

\section{As Epistemologias Freireanas}

\section{DESAFIOS CONTEMPORÂNEOS PARA O PENSAMENTO DECOLONIAL}

Os desafios apresentados por Freire e diversos outros autores críticos da dominação colonial nos oferecem novas possibilidades teóricas para contestar a autoridade de discursos e práticas coloniais que estão implicados nas relações sociais de manutenção dos privilégios e da opressão, na disputa entre os centros e as margens do poder. Os discursos decoloniais deixam claro que os antigos legados políticos da esquerda, centro e direita não podem mais ser definidos tão facilmente. De fato, os teóricos decoloniais foram mais longe e forneceram importantes percepções sobre como tais discursos se constroem ativamente nas relações patriarcais, racistas e misóginas de dominação cultural.

Nessa perspectiva, Young (1990) argumenta que o decolonialismo é um discurso deslocador que levanta questões teóricas sobre como as teorias dominantes e radicais "estão implicados na longa história do colonialismo europeu e continuam a determinar as condições de produção do conhecimento no âmbito da institucionalidade contemporânea". Isso é especialmente verdadeiro para muitos dos teóricos em uma variedade de movimentos sociais que adotaram a linguagem da diferença e uma preocupação com a política do outro. Em muitos casos, os teóricos dentro destes novos movimentos sociais têm abordado questões políticas e pedagógicas através da construção de oposições binárias que não contêm apenas traços de racismo e vanguardismo teórico, mas também caem na armadilha, simplesmente revertendo o antigo legado colonial e a problemática de oprimido vs. opressor. Ao fazer isso, eles muitas vezes imitaram inconscientemente o modelo colonial de apagar a complexidade, a cumplicidade, os diversos agentes e as múltiplas situações que constituem os enclaves do discurso e da prática colonial hegemônica.

O desafio está em desmistificar e desconstruir formas de privilégio que beneficiam a masculinidade, a brancura e a propriedade, bem como aquelas condições que impedem a circulação de outras falas nos lugares onde apenas os privilegiados, em virtude do legado do poder colonial, assumem a autoridade e as condições para a agência humana. Mais importante, educadores e trabalhadores culturais devem estar empenhados em "desaprender o próprio privilégio". O discurso decolonial reescreve a relação entre a margem e o centro, desconstruindo ideologias colonialistas e imperialistas que estruturam as práticas sociais, o conhecimento e seu registro segundo parâmetros ocidentais. Neste caso, há uma tentativa de demonstrar como a cultura europeia e o colonialismo estão profundamente implicados um no outro (Young, 1990). 
Ensino, Saúde e Ambiente - v. 14 n. esp. (2021): Dossiê Paulo Freire para além dos 100 anos: construir utopias, transformar a realidade, p. 01-21.

\section{As Epistemologias Freireanas}

Portanto, isso sugere que o desafio é mais complexo do que apenas reescrever ou recuperar as histórias reprimidas a partir das memórias do outro; significa também compreender e tornar visível a forma como o conhecimento ocidental está envolto em estruturas históricas e institucionais que excluem leituras e vozes particulares, além de estéticas, formas de autoridade, representações e modos de sociabilidade outros. Embora não se possa esquecer que o legado do colonialismo significou imperialismo cultural, morte e destruição em grande escala de outras culturas, o "outro" é muito mais do que apenas o oposto do colonizador e dos valores do Ocidente, ou apenas um tropo homogêneo do imperialismo.

Isso sugere uma terceira ruptura fornecida por discursos decoloniais. A preocupação atual com a "morte do sujeito" não pode ser confundida com a necessidade de afirmar o complexo e contraditório caráter da agência humana. O discurso decolonial nos lembra que é ideologicamente conveniente, mas politicamente suspeito para os Intelectuais ocidentais falar sobre o desaparecimento de sujeitos narradores, autônomos e falantes de dentro das instituições do privilégio e do poder. Isso não é para sugerir que teóricos decoloniais aceitam a noção humanista do sujeito como um ser unificado com identidade estática. Pelo contrário, o discurso decolonial concorda que o sujeito falante deve ser descentrado, mas isso não significa que outras noções de agência humana e transformação social devam ser descartadas. Compreendido nestes termos, a noção pós-modernista do sujeito deve ser modificada a fim de estender, ao invés vez de apagar, a possibilidade de criar condições que facilitem a agência humana. No mínimo, isso significaria compreender os pontos fortes e os limites da razão prática, a importância dos investimentos afetivos, o discurso da ética como recurso para luta social e a disponibilidade de múltiplos discursos e recursos culturais que fornecem fundamentos para a agência.

Embora essas preocupações decoloniais devam ser assumidas por aqueles que se apropriam da obra de Freire, também é necessário ser mais específico sobre a política de sua própria localização e sobre o significado que os discursos emergentes do pós-modernismo e decolonialismo assumem em seu próprio trabalho. Se Freire tem o direito de desenhar com base em suas próprias experiências, como estas poderiam ser reinventadas a fim de evitar uma apropriação colonialista por parte de teóricos do Primeiro Mundo? Ao levantar essa questão, é necessário enfatizar que o que torna o trabalho de Freire importante é que ele não é um texto a favor, mas contra o monumentalismo cultural que oferece diferentes leituras, públicos e contextos. Além disso, seu trabalho deve ser lido em sua totalidade para que se possa ter uma 
Ensino, Saúde e Ambiente - v. 14 n. esp. (2021): Dossiê Paulo Freire para além dos 100 anos: construir utopias, transformar a realidade, p. 01-21.

\section{As Epistemologias Freireanas}

melhor noção de como ele se desenvolveu na era pós-colonial. A obra de Freire não pode ser separada de sua história e também não pode ser reduzida à especificidade das intenções ou da localização histórica de determinado intelectual. Talvez o poder e a contundência das obras desse autor sejam encontrados exatamente na tensão, nos embates políticos e na poesia que o tornaram um projeto para quem cruza a fronteira, aqueles que enxergam na história uma forma de recuperar o poder e a identidade, reescrevendo o espaço e as práticas de resistência cultural e política. $\mathrm{O}$ trabalho de Freire representa uma fronteira onde a poesia desliza para a política e a solidariedade torna-se uma canção para o presente. Canção essa iniciada no passado enquanto espera para ser ouvida no futuro.

\section{CONSIDERAÇÕES FINAIS}

É preciso reconhecer que nas primeiras décadas do século XXI a conjuntura mudou. A democracia no mundo contemporâneo está sofrendo um severo ataque dos discursos fascista e neoliberal que tem a intenção de eliminá-la por completo. Sob a influência crescente de ultranacionalistas, negacionistas das mudanças climáticas e defensores do autoritarismo, os ventos ideológicos do momento nos constrangem pela substituição do ideal e da promessa de democracia pelos ditames do nacionalismo autoritário. A ignorância fabricada é uma nova face da submissão e da perda contínua da autonomia política e social. A desinformação tornou-se uma nova arma da necropolítica, espalhando medo, mentiras, ansiedade e destruição. Estas recentemente acentuadas pela pandemia de Covid-19.

A era histórica atual testemunhou uma fusão acelerada entre cultura, poder e mídias sociais, o que contribuiu para o desenvolvimento de novas formações sociais propagadoras de tsunamis de informações enganosas, produzindo o que a Organização Mundial da Saúde chamou de "infodemia". Nesse caso, as ecosferas da mídia e as máquinas de desimaginação criaram, entre grandes segmentos do público, uma fuga do pensamento crítico e da responsabilidade social. Isso é ainda mais acentuado por uma espécie do terrível silêncio e fuga do debate por parte de muitos políticos, em face da miséria e do sofrimento generalizados que se repete infinita e desnecessariamente. Essas ideologias fundamentadas na mentira obscurecem a conexão entre relações sociais prejudiciais e as configurações de poder que as moldam. Isso provoca uma falha da imaginação do público. À medida que os interesses privados prevalecem sobre o bem público, os espaços públicos são corroídos e as vantagens pessoais de curto prazo, além de uma noção regressiva de liberdade desprovida de 
Ensino, Saúde e Ambiente - v. 14 n. esp. (2021): Dossiê Paulo Freire para além dos 100 anos: construir utopias, transformar a realidade, p. 01-21.

\section{As Epistemologias Freireanas}

responsabilidade social, substituem qualquer noção mais ampla de justiça social. Tudo isso torna mais difícil para o público imaginar futuros alternativos e os horizontes de possibilidades começam a desaparecer.

As redes sociais se tornaram tóxicas, venenosas e perigosas, com um rastreamento constante de nossas necessidades, interesses, desejos e lutas políticas, espalhando mentiras e informações falsas. Mascaradas por uma nova expressão - fake news - as velhas ideologias conservadoras que alinham a consciência individual e coletiva com as forças do autoritarismo voltam a emergir. A ignorância fabricada se funde com um lote horrível de emoções preconceituosas e odiosas disseminadas entre milhões de pessoas simultaneamente, como uma corrente elétrica. A política não é mais simplesmente uma luta por instituições econômicas, dispositivos culturais ou relações coloniais de poder, é também uma luta por ideias, consciência, identidade e agência. A cultura popular está agora nas mãos de um número limitado de corporações com alcance global ameaçando todo o planeta. A praga da ignorância fabricada emerge numa arena política que é agora amplamente definida pela manipulação da cultura popular e pela repercussão de ideologias fascistas pelas poderosas mídias de direita.

$\mathrm{Na}$ era do espetáculo, as ferramentas da educação e do pensamento crítico devem ser elevadas ao centro da política. Urge, portanto, um movimento revitalizado de recuperação da linguagem de uma democracia substantiva, dedicado à criação de visões, ideais, instituições, relações sociais e formas de resistência coletiva que permitam ao público imaginar uma vida para além de uma ordem social que naturalize as violências de classe, gênero e raça, legitimando uma cultura de crueldade (HOOKS, 1989; 1990). A educação é a base da política, e a cultura formativa que ela produz é a esfera onde as pessoas se tornam politicamente alfabetizadas ou civicamente analfabetas. Esquecer isso é dar à extrema direita uma vantagem na guerra cultural que pode ser impossível de reverter. As apostas são altas demais para permitirmos que isso aconteça.

É exatamente por isso que a obra de Paulo Freire volta a adquirir, no contexto contemporâneo, relevância cada vez maior. O fundamental na obra de Freire e nas suas lutas por liberdade e transformação social foi o reconhecimento de que a dominação não era apenas econômica e estrutural, mas também pedagógica, ideológica, cultural e intelectual e que questões de persuasão e crença eram armas cruciais para a criação de agentes engajados e sujeitos críticos. Ele também refutou a rota de fuga fácil dos cínicos que igualaram e colapsaram a dominação e o poder. A resistência sempre foi uma possibilidade e qualquer 
Ensino, Saúde e Ambiente - v. 14 n. esp. (2021): Dossiê Paulo Freire para além dos 100 anos: construir utopias, transformar a realidade, p. 01-21.

\section{As Epistemologias Freireanas}

política que a negasse carregaria o peso da cumplicidade com os crimes mais hediondos e não reconhecidos. Freire foi um intelectual público transformador e um lutador pela liberdade que acreditava que os educadores tinham a enorme responsabilidade de enfrentar os problemas sociais e políticos mais importantes de seu tempo, de dizer a verdade e de correr riscos, por mais inconvenientes que fossem as consequências. A coragem cívica era essencial para a política e ele personificava o melhor dessa convicção.

Freire acreditava que nenhuma sociedade deve ter apenas o suficiente para sobreviver e que a luta contra a injustiça e a opressão institucional é a pré-condição para uma política global de radicalização dos valores democráticos. A alfabetização política para ele foi uma arma para despertar a consciência, encorajar a ação cívica e encerrar a atração de uma política fascista. Freire era perigoso e com razão. Em um momento em que a história está sendo apagada, aqueles considerados descartáveis estão perdendo suas vidas. Há a necessidade, mais do que nunca, do despertar de uma consciência anticapitalista e de um movimento social de massa. $\mathrm{O}$ espírito e a política de Freire não devem ser somente celebrados com alegria, mas imitados e fortalecidos em torno da construção de uma nova ética decolonial, livre, transformadora e, por tudo isso, revolucionária. Viva Paulo Freire. E vivamos sua obra no sentido mais radical que ela representa, com todo seu significado político de resistência e luta decolonial.

\section{REFERÊNCIAS}

BORSA, J. "Towards a Politics of Location: Rethinking Marginality." Canadian Women Studies 11: 36-39, 1990.

FALS-BORDA, O. Revoluções inacabadas na América Latina 1809-1968. México: Editores Siglo XXI, 1968.

FALS-BORDA, O. Instituto de Pesquisa Participativa do Homem. 2a Ed. Montevidéu: Edições da Banda Oriental, 1987.

FALS-BORDA, O. Origens universais e desafios atuais do IAP. Análise política. Colômbia: Instituto de Estudos Políticos e Relações Internacionais (IEPRI), 1999.

FALS-BORDA, O. Ação e Espaço. Autonomia na Nova República. Bogotá: Tercer Mundo Editores, 2000

FALS-BORDA, O. A Sentipensante Sociology for Latin America. Buenos Aires. Século XXI Editora e CLACSO, 2015. http: // biblioteca. clacso. edu.ar/clacso/se/20151027053622/AntologiaFalsBorda.pdf . 
Ensino, Saúde e Ambiente - v. 14 n. esp. (2021): Dossiê Paulo Freire para além dos 100 anos: construir utopias, transformar a realidade, p. 01-21.

As Epistemologias Freireanas

FALS-BORDA, O. Pesquisa-ação em convergências disciplinares. [Disponível apenas via Internet em: Http://Historiactualdos.Blogspot.Com/2008/11/La-InvestigacinAccin-EnConvergencias.Html

FECODE. Pesquisa-ação-participativa: teoria e análise política. Caderno Temático $\mathrm{n}^{\mathrm{o}} 1$. Bogotá: Federação Colombiana de Educadores (FECODE), 2006.

FIGUEIREDO, G. Pesquisa-ação participativa: uma alternativa para a epistemologia social na América Latina Pesquisa-ação participativa: uma opção pela epistemologia social na América Latina. Revista de Pesquisa (Caracas). № 86, v.39, set-dez, p.255-273, 2015. http://ve.scielo.org/pdf/ri/v39n86/art14.pdf

FREIRE, P. Política e Educação: Ensaios. São Paulo: Cortez, 1993.

FREIRE, P. Ação Cultural para a Liberdade e Outros Escritos. 4 para Edição. São Paulo, Paz e Terra, 1979.

FREIRE, P. Conscientização, teoria e prática da libertação: uma introdução ao pensamento de Paulo Freire. $3^{\text {a }}$ ed. São Paulo: Centauro, 1980.

FREIRE, P. Pedagogia do oprimido. 17 Ed. Rio de Janeiro: Paz e Terra, v. 3, 1987.

FREIRE, P. Pedagogia da Autonomia - Conhecimentos Necessários à Prática Educativa. $14^{a}$ ed. Rio de Janeiro: Paz e Terra, 1997.

FREIRE, P; MACEDO, D.. Literacy: Reading the Word and the World_ South Hadley, MA: Bergin, 1987.

FREIRE, P; FAUNDEZ, A. Learning to Question: A Pedagogy of Liberation. New York: Continuum, 1989.

FREIRE, P. Cartas à Guiné-Bissau: registros de uma experiência em processo. Editora Paz e Terra, 2014.

FREIRE, P. Pedagogy of hope: Reliving pedagogy of the oppressed. Bloomsbury Publishing, 2021.

GIROUX, H. Paulo Freire e a política do pós-colonialismo. Journal of Advanced Composition, v12, n1, p15-26, Win. 1992a.

GIROUX, H. A Border Crossings: Cultural Workers and the Politics of Education. New York: Routledge, 1992b.

HOOKS, B. Talking Back: Thinking Feminist, Thinking Black. Boston: South End, 1989.

HOOKS, B. Yearning: Race and Gender in the Cultural Marketplace. Boston: South End, 1990.

HORTON, M; FREIRE, P. We Make the Road by Walking: Conversations on Education and Social Change. Ed. Brenda Bell, John Gaventa, and John Peters. Philadelphia: Temple UP, 1990.

LACLAU, E. "Building a New Left: An IntelViewwith Ernesto Laclau." Strategies 1 (1988): $10-28$.

LEONARD, P; MCLAREN, P . Paulo Freire: A critical encounter. Routledge, 2002. 
Ensino, Saúde e Ambiente - v. 14 n. esp. (2021): Dossiê Paulo Freire para além dos 100 anos: construir utopias, transformar a realidade, p. 01-21.

\section{As Epistemologias Freireanas}

MIGNOLO, W. Desobediência epistêmica: uma opção descolonial e o significado da identidade na política. Cadernos de Letras da UFF - Dossiê: Literatura, Língua e Identidade, vol. 34, pág. 287-324, 2008.

ORTIZ, M.; BORJAS, B. Pesquisa-ação participativa: contribuições de Fals Borda para a educação popular. Rev. Espacio Abierto, 17 (4), 615-627, 2008.

PARRY, B. "Problems in current theories of colonial discourse." Oxford literary review 9, no. 1 (1987): 27-58.

PESTAÑA, J .; ALCÁZAR, MA (2009). Pesquisa-ação-participativa. Em: ROMÁN; Reyes (Org). Dicionário Crítico de Ciências Sociais . Terminologia Científico-Social , Volume 3, Madrid-México: Editora Plaza y Valdés.

QUIJANO, A. Questões e horizontes da dependência histórico-estrutural da colonialidade / descolonialidade do poder. Coleção de Antologias do Conselho LatinoAmericano de Ciências Sociais. Buenos Aires: CLACSO, 2014.

RESTREPO, E; ROJAS, A. Inflexão descolonial: fontes, conceitos e questões. Universidade de Cauca, Popayán, Colômbia, outubro de 2010. SHOR, Ira;

FREIRE, P. A pedagogy for liberation: Dialogues on transforming education. Greenwood Publishing Group, 1987.

STYGALL, G. "Teaching Freire in North America." Journal of Teaching Writing 8 (1989): 113- 25.

YOUNG, R. White Mythologies: Writing History and the West. New York: Routledge, 1990.

\section{SOBRE OS AUTORES}

\section{HENRY ARMAND GIROUX}

Estudioso e crítico cultural americano. Um dos primeiros teóricos da pedagogia crítica nos Estados Unidos, é conhecido por seu trabalho pioneiro, em pedagogia, estudos culturais, estudos de juventude, educação superior, estudos de mídia e a teoria crítica.

\section{GUSTAVO DE OLIVEIRA FIGUEIREDO}

Professor e Pesquisador da Universidade Federal do Rio de Janeiro e Professor Visitante na McMaster University (Canada). Experiência na interseção das áreas de Ciências Humanas, Ciências Sociais e Ciências da Saúde com ênfase nos campos de Educação, Saúde e Cultura. Credenciado no programa de pós-graduação do Instituto NUTES de Educação em Ciências e Saúde. Interesses de pesquisa: i) Políticas Públicas de Educação e Saúde; ii) Trabalho e Educação em Saúde: Teorias, Métodos e Práticas; iii) Ensino na Educação Superior em Saúde; iv) Avaliação e Qualidade da formação em saúde e; v) História de Vida e Identidade Profissional de professores e profissionais de saúde; vi) Práxis Educativa, Transdisciplinaridade e Promoção da Saúde: Ação Coletiva Intersetorial, Educação Popular em Saúde, Vulnerabilidade Social, Autonomia dos sujeitos e Empoderamento Comunitário; vii) Psicologia da Comunicação: intersubjetividade, Interação Social e Desenvolvimento Humano; viii) Trabalho Docente, Práticas de Ensino e Formação de Professores; ix) Métodos de Pesquisa em Educação, Pesquisa-ação e Pesquisa-participativa; x) Epistemologia Social e Teorias do Pensamento Crítico e pós-crítico na América Latina. 